\title{
IdeAs
}

Idées d'Amériques

$17 \mid 2021$

Villes et culture dans les Amériques

\section{Développement économique urbain et (in)visibilité des cultures autochtones : les Sioux lakota à Rapid City, SD}

Urban economic development and indigenous cultures: the case of the Lakota Sioux in Rapid City, SD

Desarrollo económico urbano y culturas indígenas: el caso de los Sioux Lakota en Rapid City, SD

\section{Sandrine Baudry et Céline Planchou}

\section{OpenEdition}

\section{Journals}

Édition électronique

URL : https://journals.openedition.org/ideas/10938

DOI : 10.4000/ideas.10938

ISSN : $1950-570$

Éditeur

Institut des Amériques

Référence électronique

Sandrine Baudry et Céline Planchou, « Développement économique urbain et (in)visibilité des cultures autochtones : les Sioux lakota à Rapid City, SD », IdeAs [En ligne], 17| 2021, mis en ligne le 16 mars 2021, consulté le 04 juin 2021. URL : http://journals.openedition.org/ideas/10938 ; DOl : https:// doi.org/10.4000/ideas. 10938

Ce document a été généré automatiquement le 4 juin 2021

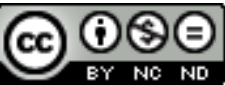

IdeAs - Idées d'Amériques est mis à disposition selon les termes de la licence Creative Commons Attribution - Pas d'Utilisation Commerciale - Pas de Modification 4.0 International. 


\title{
Développement économique urbain et (in)visibilité des cultures autochtones : les Sioux lakota à Rapid City, SD
}

\author{
Urban economic development and indigenous cultures: the case of the Lakota \\ Sioux in Rapid City, SD \\ Desarrollo económico urbano y culturas indígenas: el caso de los Sioux Lakota en \\ Rapid City, SD
}

Sandrine Baudry et Céline Planchou

\section{Introduction}

1 Rapid City, située dans le Dakota du Sud au pied de Paha Sapa (Black Hills en lakota) et son célèbre Mont Rushmore, est ce que les chercheurs en études autochtones appellent une border town. Dans ce contexte, les villes frontières sont définies par leur proximité géographique et historique avec des réserves amérindiennes, et caractérisées aujourd'hui encore par la peur et la violence coloniale (US Commission on Civil Rights, $2011: 2$; Estes N., 2019). L'idée d'autochtonie et celle d'urbanité sont très largement opposées aux États-Unis (Andersen C., 2015). La ville étant historiquement le site privilégié de l'assimilation, l'invisibilisation des Amérindiens y est monnaie courante (Porter L. et 0. Yiftachel, 2019; Weaver H., 2012), mais nulle part autant que dans ces border towns. En effet, celles-ci les ont activement repoussés aux marges de l'espace urbain et les ont exclus du récit historique fantasmé de leur genèse. Ceci leur a permis de mieux nier l'existence de ceux dont elles ont accaparé les terres

2 Aujourd'hui, cette petite ville de soixante-quinze mille habitants, longtemps attachée à son histoire mythifiée d'avant-poste de la Frontière est en quête d'une identité nouvelle pour se vendre et retenir les touristes de passage vers l'Ouest et attirer les 
investisseurs et résidents permanents. Dans ce contexte, l'image de l'Indien ${ }^{1}$, exploitée depuis les débuts dans sa dualité fascinante et menaçante, est intégrée aux projets de développement économique, notamment dans le centre-ville. La redynamisation urbaine et le développement économique, ouvertement axés sur le tourisme et la culture artistique locale, peuvent-ils permettre de dépasser cette dualité caricaturale et figée dans un passé fantasmé? Peuvent-ils ainsi transformer des rapports de domination violents qui se traduisent par de nombreuses inégalités socio-économiques et des discriminations spatiales et sociales systémiques?

Depuis une quinzaine d'années, une partie des études autochtones s'intéresse au concept de colonialisme de peuplement (settler colonialism) dans l'analyse de phénomènes contemporains (Wolfe P., 2006; Byrd J., 2011; Barnd N., 2017). Pour Patrick Wolfe, les logiques qui sous-tendent ce colonialisme, défini comme une entreprise qui cherche à "détruire pour remplacer» (Wolfe P., 2006: 388), sont toujours opérantes et informent les rapports de domination inscrits dans les espaces nord-américains, y compris urbains. Certains chercheurs invitent ainsi à repenser l'idée selon laquelle "la ville et la réserve sont deux espaces totalement déconnectés » (Dorries $\mathrm{H}$, et al, 2019: 2). Selon eux, cette déconnexion produite par le discours colonial «permet aux villes contemporaines de se dissocier de la longue histoire des relations spatiales entre les autochtones et les colons dont elles sont pourtant invariablement issues ", et ainsi de se penser comme des espaces ontologiquement nonautochtones et étrangers aux conflits territoriaux actuels tout en niant les violences structurelles qui découlent des « logiques d'élimination " propres à ces espaces urbains (9-12.) Par ailleurs, alors que l'UNESCO lance en 2015 un projet autour de la culture et $\mathrm{du}$ développement urbain durable, les études urbaines récentes analysent la tension entre valorisation et instrumentalisation de pratiques culturelles à des fins de développement économique (Dinardi C., 2017). Notre étude de cas s'inscrit à la croisée de ces deux mouvements théoriques.

Elle est par ailleurs basée sur des données de terrain (observations, entretiens semidirectifs, archives municipales) recueillies lors de trois séjours d'un mois entre 2015 et 2017, ainsi que sur la presse locale et des documents officiels obtenus depuis en ligne. Durant les séjours de recherche, nous avons rencontré de manière plus ou moins formelle, sur rendez-vous ou lors d'observations, des résidents de Rapid City et des réserves alentour, des acteurs associatifs et institutionnels, des artistes et des commerçants. Les données primaires sont analysées à la lumière d'une littérature pluridisciplinaire sur les études autochtones et les études urbaines, et d'une réflexion plus large sur les récits historiques et imaginaires géographiques en conflit sur le territoire de la Grande Réserve Sioux.

5 Nous allons dans un premier temps présenter l'histoire de Rapid City et la manière dont les dynamiques paradoxales d'exclusion et d'exploitation se sont mises en place. Nous aborderons ensuite les initiatives de redynamisation économique du centre-ville et la place accordée à la culture lakota, puis nous verrons que cette place reste relative. L'article se termine par une discussion des raisons pour lesquelles ces évolutions récentes ne suffisent pas à réellement transformer les logiques de marginalisation des Lakotas. 


\section{Contextualisation : Rapid City et les Lakotas}

6 La ville de Rapid City est à l'origine un campement établi illégalement au cœur de la Grande Réserve Sioux, un territoire défini par les traités de Fort Laramie de 1851 et 1868. Après la découverte de filons aurifères dans Paha Sapa, un lieu qui revêt une forte dimension spirituelle pour les Lakotas et différentes nations autochtones de la région, les chercheurs d'or affluent, empiétant ainsi progressivement sur les terres réservées aux Amérindiens. Rapid City, à l'origine appelée Hay Camp, est fondée en 1876. Idéalement située au pied de Paha Sapa, elle devient rapidement une plaque tournante de l'économie locale. C'est ainsi une étape obligée pour les chariots qui ravitaillent les campements, illégaux eux aussi, tels Deadwood. Les tensions entre colons et Amérindiens s'intensifient et, très vite, Rapid City se retrouve de fait «sortie » de la réserve, à mesure que les frontières du territoire lakota sont redéfinies par l'État fédéral. La distance se creuse davantage en 1889, lorsque ce dernier décide de morceler la Grande Réserve Sioux en six réserves, répondant ainsi à la pression foncière et ferroviaire. Cet éloignement progressif permet à la ville de se construire comme un espace non-indien, entièrement tourné vers l'industrie minière de Paha Sapa plus à l'Ouest, niant ainsi son origine illégale et effaçant dans le même temps la présence autochtone désormais rattachée aux seules réserves (Hall P., 1991).

7 Pourtant, les Amérindiens sont bien présents dans la ville. Ils sont tout d'abord à l'ouest de Rapid City, près de terres qui appartiennent à l'État fédéral et sur lesquelles celui-ci ouvre, en 1898, un pensionnat pour les enfants des réserves avoisinantes qui deviendra par la suite un hôpital (Sioux San). Beaucoup s'installent également sur les berges de Mni Luzahan (Rapid Creek en lakota), là où, en 1876, Hay Camp avait été fondé. Ce choix n'est pas anodin puisque depuis des générations, c'était un lieu privilégié par les Lakotas pour leurs rassemblements annuels. De leur côté, les résidents nonamérindiens avaient rapidement délaissé Hay Camp, déplaçant le cœur économique de la ville un peu plus loin, vers Main Street (Tallent A., 1899). Ainsi, au fil des décennies, les Lakotas ont été marginalisés spatialement dans un double mouvement: le centre urbain s'est éloigné de leurs campements devenus ghettos (Kotatv, 2018), et eux-mêmes ont été repoussés vers Lakota Homes et Sioux Addition, des quartiers ségrégués insalubres, les «pires bidonvilles du Midwest » (Janson D., 1962), bâtis au nord des limites de la ville dans les années 1950 et 1960. Depuis, l'expansion de la municipalité les a absorbés, mais "North Rapid ", où les Amérindiens vivent encore en majorité, conserve une image négative de ghetto dangereux.

Parallèlement à cette marginalisation spatiale, visant au cours des décennies à nier la présence amérindienne en invisibilisant les corps, l'image de l'Indien, elle, n'a cessé d'être exploitée dans sa dualité. Dès le xix siècle, l'industrie du tourisme s'est appuyée sur l'image positive du sauvage paradant à dos de cheval et arborant tenues et objets culturels traditionnels. Ainsi, dans les années 1930, des danses et des cérémonies étaient présentées comme des spectacles pour touristes tous les soirs au centre de Rapid City (Rapid City Chamber of Commerce, 1932; Barta-Julin S., 2005 : 298). Cette mise en scène mercantile de l'Indien sauvage et "authentique", mais dorénavant inoffensif, allait le figer dans un passé incompatible avec la modernité incarnée par la ville alors en pleine expansion économique et technique. Paradoxalement, la mise en lumière de cet Indien dans l'espace urbain servait donc à renforcer l'invisibilité des Amérindiens qui y vivaient réellement. 
Si l'industrie du tourisme a rapidement tiré profit de cette dimension positive et attractive de l'Indien "authentique ", dans les années 1970, c'est l'image négative de l'Indien hostile, menaçant toujours l'état de fait colonial par la soi-disant violence de ses discours et de ses actes, qui allait être exploitée cette fois dans la presse locale. Au moment où des résidents de la réserve voisine de Pine Ridge et des membres de l'American Indian Movement (AIM) occupent le village de Wounded Knee, un climat de défiance est entretenu. On craint l'agitation politique, incarnée par le militantisme de AIM, qui déborde des frontières des réserves et jette le trouble dans la ville en « terrorisant » la population locale (Kentfield C., 1973). Depuis la création de Rapid City, la tension entre la marginalisation des corps autochtones et l'exploitation des différentes facettes de l'Indien réifié a ainsi toujours été à l'œuvre.

\section{Redynamisation du centre-ville et visibilité autochtone}

Historiquement, les Lakotas ont été repoussés physiquement aux marges de la ville au fur et à mesure de l'expansion de celle-ci, en même temps que se construisaient un discours et des pratiques de rejet couvrant le spectre de la violence du symbolique au létal. On peut se demander si la dialectique inverse peut s'opérer : le fait de permettre, voire d'encourager la visibilité des Amérindiens au centre-ville va-t-il nécessairement de pair avec une meilleure acceptation de leur présence dans l'espace urbain?

Figure 1

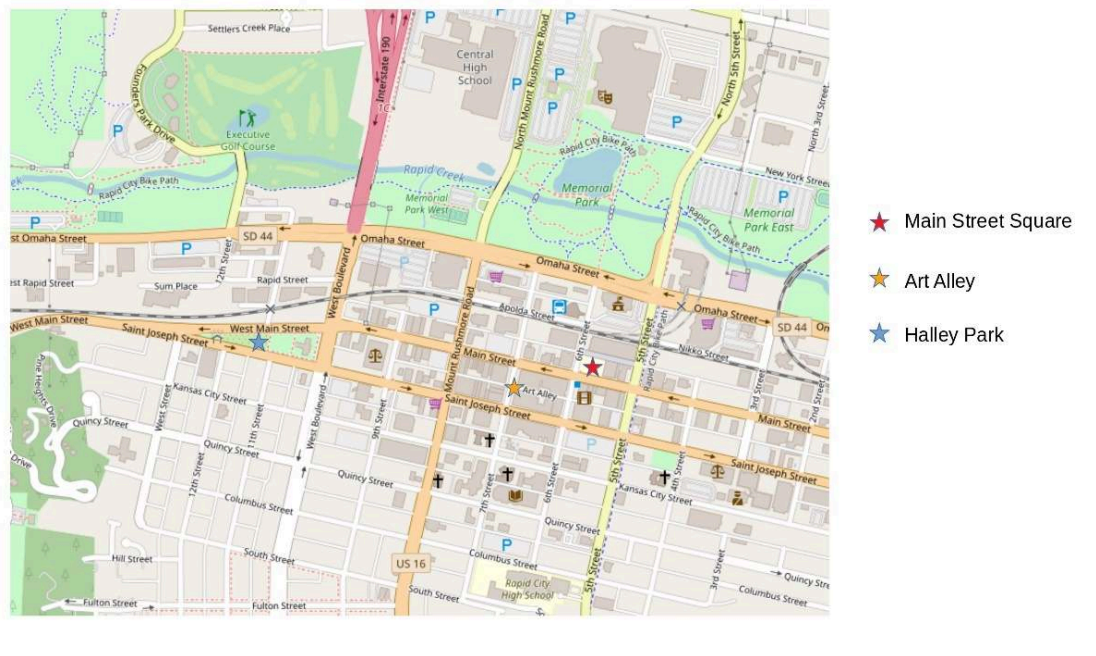

Plan du centre de Rapid City, Open Street Map

Source : Sandrine Baudry et Céline Planchou

\section{Le projet du Central Business District}

11 On observe aujourd'hui à Rapid City le type de redynamisation propre aux villes américaines après les pertes de population et de commerces induites par la montée en puissance de la périurbanisation à partir des années 1950 (Polèse M., 2014). En 1949, le plan de développement de Rapid City, tout en vantant les mérites de l'automobile, souligne l'importance des revenus liés aux impôts versés par les commerces et 
entreprises du centre-ville, et le potentiel économique lié au tourisme, déjà bien présent dans Paha Sapa grâce au Mont Rushmore. Plus récemment, avec l'avènement du marketing territorial et du city branding, ce sont des consultants en tourisme qui ont été mobilisés pour identifier les faiblesses et les forces de la ville afin de développer une identité unique et marchandisable (Anttiroiko A-V., 2015), particulièrement indispensable au développement économique des petites villes qui doivent lutter contre l'idée de banalité qui leur est souvent associée (Mainet H., $2008: 18$ ).

C'est dans ce contexte qu'en 1996 des panneaux ont été érigés dans le centre historique pour mettre en valeur le passé pionnier de la ville (sans aucune mention des Lakotas) mais également inciter les automobilistes à quitter leurs véhicules et à circuler à pied, afin d'encourager la fréquentation des commerces et restaurants (Daly D., 1996). À partir de 2000, sous l'impulsion de Don Perdue, un commerçant local, des statues de présidents ont été placées à chaque coin de rue, en écho à la proximité du célèbre Mont Rushmore; c'est ainsi qu'est née l'identité de "Ville des Présidents ", malgré des protestations initiales car le comité de l'art public de la ville n'avait pas été consulté, ce à quoi il a été répondu qu'il ne s'agissait pas d'art, mais d'économie 2 .

13 La création de Destination Rapid City en 2008 marque le début du grand projet de renouvellement du centre-ville toujours en cours actuellement. Cette organisation, rassemblant commerçants et entrepreneurs, a commissionné Roger Brooks, « expert en destination ", pour effectuer un diagnostic et faire des propositions pour rendre Rapid City plus attractive (Lawrence T., 2008) - une stratégie typique de l'urbanisme néolibéral (Sager T., 2011). En 2010 a été créé un Business Improvement District (BID) afin de récolter les impôts nécessaires au financement de ces projets et d'en assurer une gestion unifiée et cohérente. C'est ainsi qu'en 2011 est né Main Street Square sur le site d'un parking, l'unique place publique centrale dont la présence était préconisée depuis le début des années 1990 pour rendre le centre plus dynamique et attractif.

On constate par ailleurs une meilleure prise en compte des Amérindiens dans les plans d'urbanisme depuis le rapport de 1949. Celui-ci mentionnait uniquement le fait que la zone de Mni Luzahan, occupée par les campements lakotas alors appelés à tort «Indian Reservation" (appellation qui souligne le statut de population ségréguée et marginalisée) devrait être rachetée par la municipalité pour des raisons sanitaires, afin d'y fonder le Rapid Creek Park (p. 54). Dans le rapport de 2014 est en revanche soulignée la nécessité de préparer la ville à une augmentation de la population lakota, de développer les transports publics vers North Rapid, ou encore de créer des logements adaptés à la notion de famille élargie propre à la culture lakota. Cependant, ces points relèvent presque tous de demandes faites lors de consultations publiques à Lakota Homes, et ne sont pas le fait d'initiatives municipales. Il n'en reste pas moins que, jusqu'à aujourd'hui, tous les rapports regroupent l'essentiel des recommandations concernant la population lakota dans la rubrique " projet culturel ». Il peut s'agir tout aussi bien de créer des galeries ou de l'art public, ou de mettre en avant cette facette de l'identité de Rapid City et espérer en faire le "Santa Fé des Plaines », centre artistique et culturel amérindien reconnu internationalement ${ }^{3}$. Dans tous les cas, ces ambitions soulignent l'affinité entre dynamiques artistiques et dynamiques urbaines soulignée entre autres par Can-Seng Ooi (2017). 


\section{Des espaces « publics » et des moments festifs autour de la culture et des arts}

15 Le projet de redynamisation porté par Destination Rapid City a indéniablement changé le centre-ville. Main Street Square est occupée, de nouveaux commerces ouvrent dans les rues alentour, des initiatives d'embellissement voient le jour ${ }^{4}$. Par ailleurs, Destination Rapid City incluait initialement une entité nommée Arts Rapid City, ensuite intégrée au Rapid City Arts Council. On voit donc bien ici à quel point le projet artistique et culturel est étroitement lié à l'économique.

\section{Main Street Square}

Cette place est conçue comme un lieu de rassemblement célébrant la diversité de la communauté; et inclut des symboles forts de l'identité unique de la ville telle que vendue aux touristes, à savoir une genèse ancrée dans le mythe de l'Ouest, entre Paha Sapa et les Grandes Plaines, sur le territoire lakota. On trouve ainsi à l'entrée principale une grande medicine wheel ${ }^{5}$ peinte sur le sol, et tout autour de cet espace public, des pierres sculptées par Masayuki Nagase pour représenter les deux écosystèmes de la région, les plaines et les collines ${ }^{6}$. Cette représentation, élaborée par un artiste venu de l'extérieur, replace la ville au centre de la Grande Réserve Sioux, en contradiction avec le récit mythique d'une ville de courageux pionniers, tournée vers l'Ouest. Cette place, financée en partie par la municipalité à ses débuts, mais qui se vante aujourd'hui en première page de son site de ne recevoir aucun subside public, est entretenue grâce aux revenus fiscaux du BID et à la location du lieu pour des événements ponctuels. Malgré cette gestion privée assumée, il s'agit bien d'un espace destiné à l'usage public. En effet, les tables et chaises, le wifi gratuit, les fontaines dynamiques qui font le bonheur des enfants en été, ainsi que sa position centrale à proximité de nombreux commerces et restaurants, permettent une fréquentation constante par les résidents de la ville, comme par les touristes (Figure 2). La gratuité de la plupart des événements qui y sont organisés (séances de cinéma, expositions, etc.) est également l'opportunité d'une mixité socio-économique. 
Figure 2

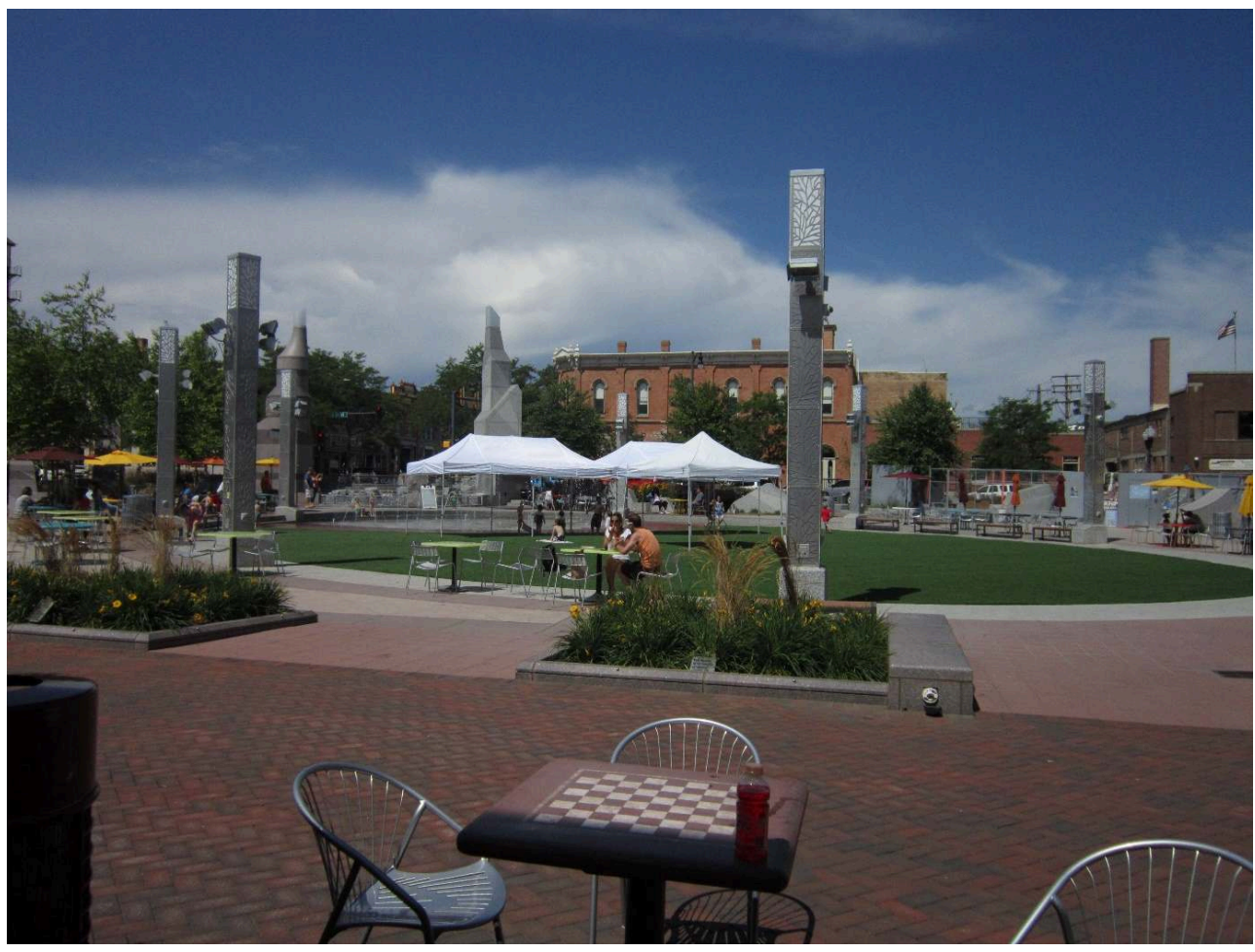

Main Street Square, 16 juillet 2015

Source : Sandrine Baudry et Céline Planchou

\section{Art Alley}

Le second espace significatif pour l'expression artistique et la présence des corps amérindiens est Art Alley. Il s'agit d'une petite ruelle idéalement située pour être intégrée dans le projet culturel et économique de Destination Rapid City (figure 1). Ses murs étaient déjà tagués depuis longtemps quand en 2003 un artiste local a proposé à la Ville d'en faire un lieu d'embellissement créatif, projet soutenu entre autres par Don Perdue. En 2013, la Art Alley Artist Guild est créée pour " gérer le crime, les graffitis et la propreté $»^{7}$. Enfin, depuis 2016, il est nécessaire de demander un permis de peindre, en échange de quoi Destination Rapid City fournit la peinture gratuitement. Cette décision, destinée à limiter le vandalisme et les graffitis inappropriés ${ }^{8}$, soulève la question de la nature contre-culturelle de l'art de rue. Mais le potentiel de contestation politique du graffiti (Waldner L. et B. Dobratz, 2013) demeure effectif pour les Lakotas, notamment par l'utilisation de leur langue, ou la représentation de symboles forts liés à leur histoire et leur culture (figure 3). On trouve en particulier des références récurrentes aux revendications territoriales, rappelant à l'observateur non-amérindien qu'il est ici en terre autochtone (figure 4). 
Figure 3

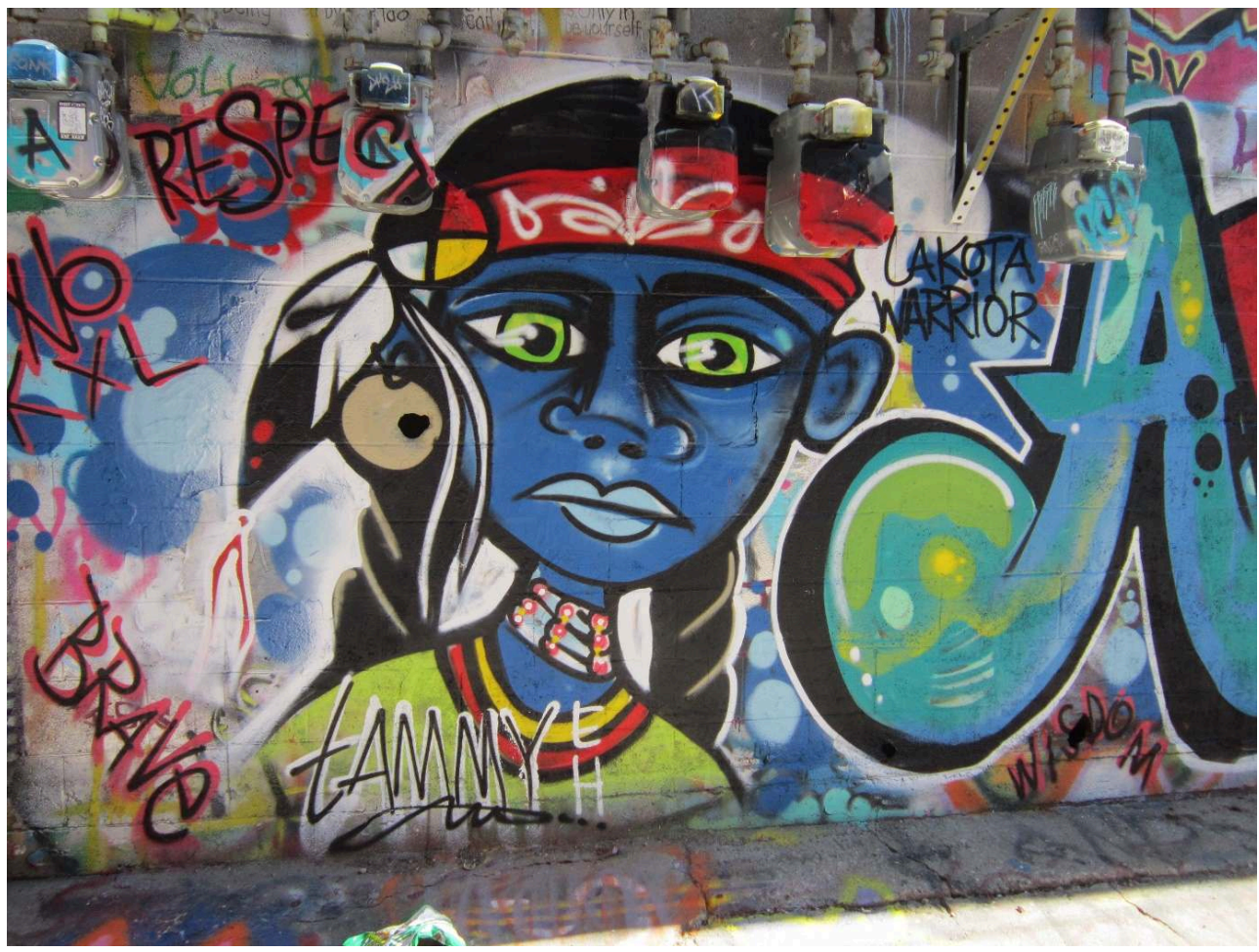

Graffiti d'une artiste lakota dans Art Alley, 12 juillet 2015

Source : Sandrine Baudry et Céline Planchou 
Figure 4

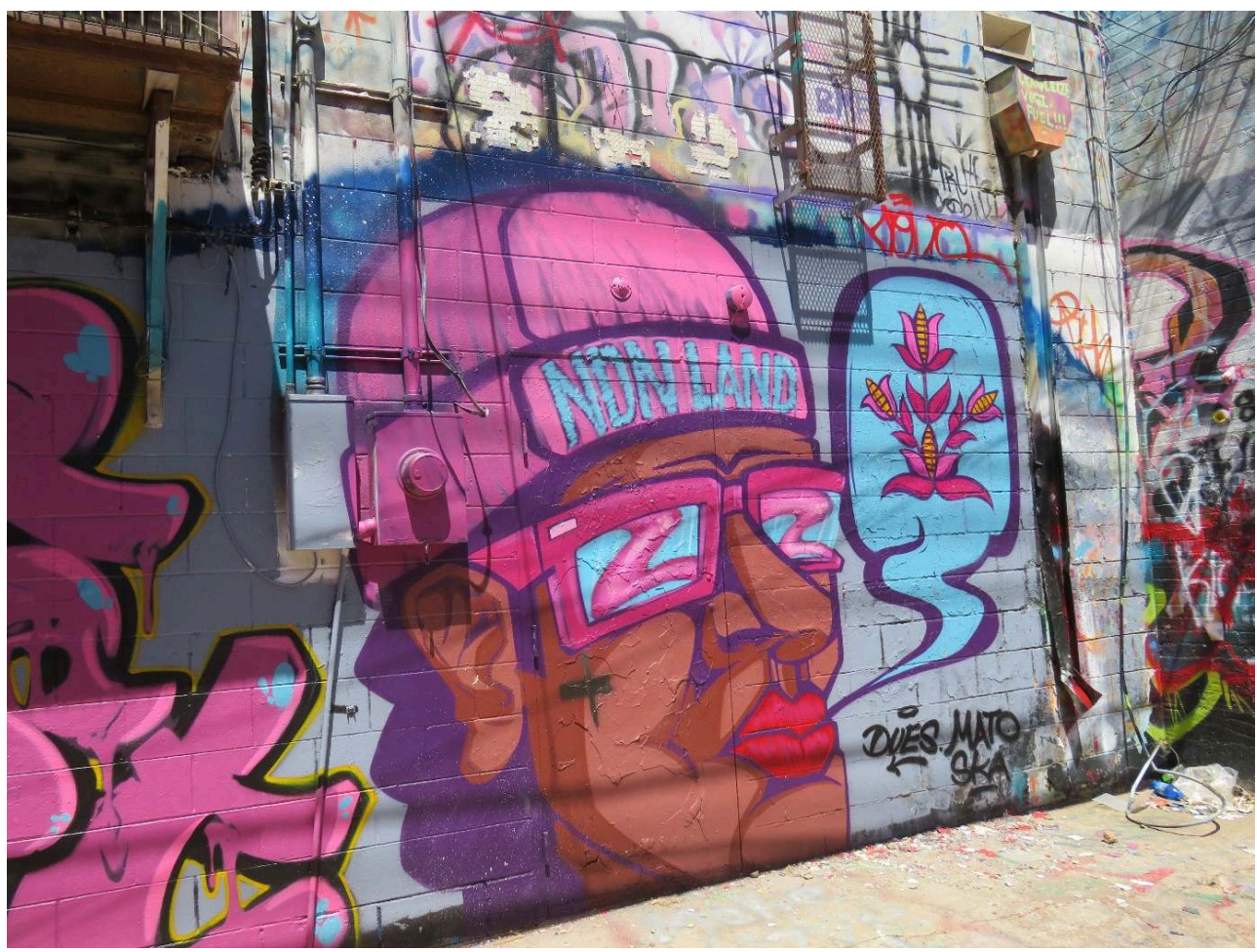

NDN Land (phonétiquement «Indian land »), expression couramment utilisée par les Amérindiens aux États-Unis, 10 juillet 2016

Source : Sandrine Baudry et Céline Planchou

\section{Summer Nights et Native POP}

Ce nouveau centre-ville, par le nombre d'événements culturels gratuits qui y sont organisés, offre des opportunités ponctuelles pour la présence et l'expression autochtones. Par exemple, lors des Summer Nights, un festival de musique qui depuis 2008 propose des concerts gratuits tous les jeudis soir en été (RC Summer Nights), de nombreux Amérindiens sont présents dans la rue, notamment dans Art Alley. Ce phénomène, rare en temps normal, pourrait participer à normaliser la présence de ces corps lakotas au moins pendant la saison touristique.

19 Mais c'est surtout Native POP (People of the Plains) ${ }^{9}$ qui offre une visibilité importante et multiforme aux cultures amérindiennes comme aux individus. Ce festival propose chaque été, pendant une journée, des concerts, des films, des lectures de poèmes. On peut y acheter tableaux contemporains et bijoux, mais certains " passeurs de cultures » refusent de marchandiser leurs pratiques traditionnelles et viennent uniquement en faire la démonstration, par exemple l'ornementation de mocassins avec des perles ou des épines de porcs-épics, ou le quilt. Le festival se déroule essentiellement sur Main Street Square, à l'entrée duquel est installée pour l'occasion l'armature d'un tipi (Figure 5). Il a pu voir le jour grâce à la création de cet espace public, puisque la première année (alors appelé Gathering of Wind, Water and People), il a été financé par une bourse remise par le sculpteur Masayuki Nagase pour encourager les projets en lien avec les communautés locales ${ }^{10}$. Si tous les artistes participant au festival doivent répondre à la définition légale de l'artiste amérindien, à savoir l'affiliation à une tribu reconnue par l'État Fédéral ${ }^{11}$, le festival est en revanche ouvert à tous, et c'est l'occasion d'échanges 
non seulement monétaires mais culturels, de discussions, d'expression plus ou moins ouvertement politique, que ce soit par les œuvres d'art exposées, les concerts ou les tshirts portés par le public, souvent ornés de drapeaux tribaux ou revendications autochtones.

Figure 5

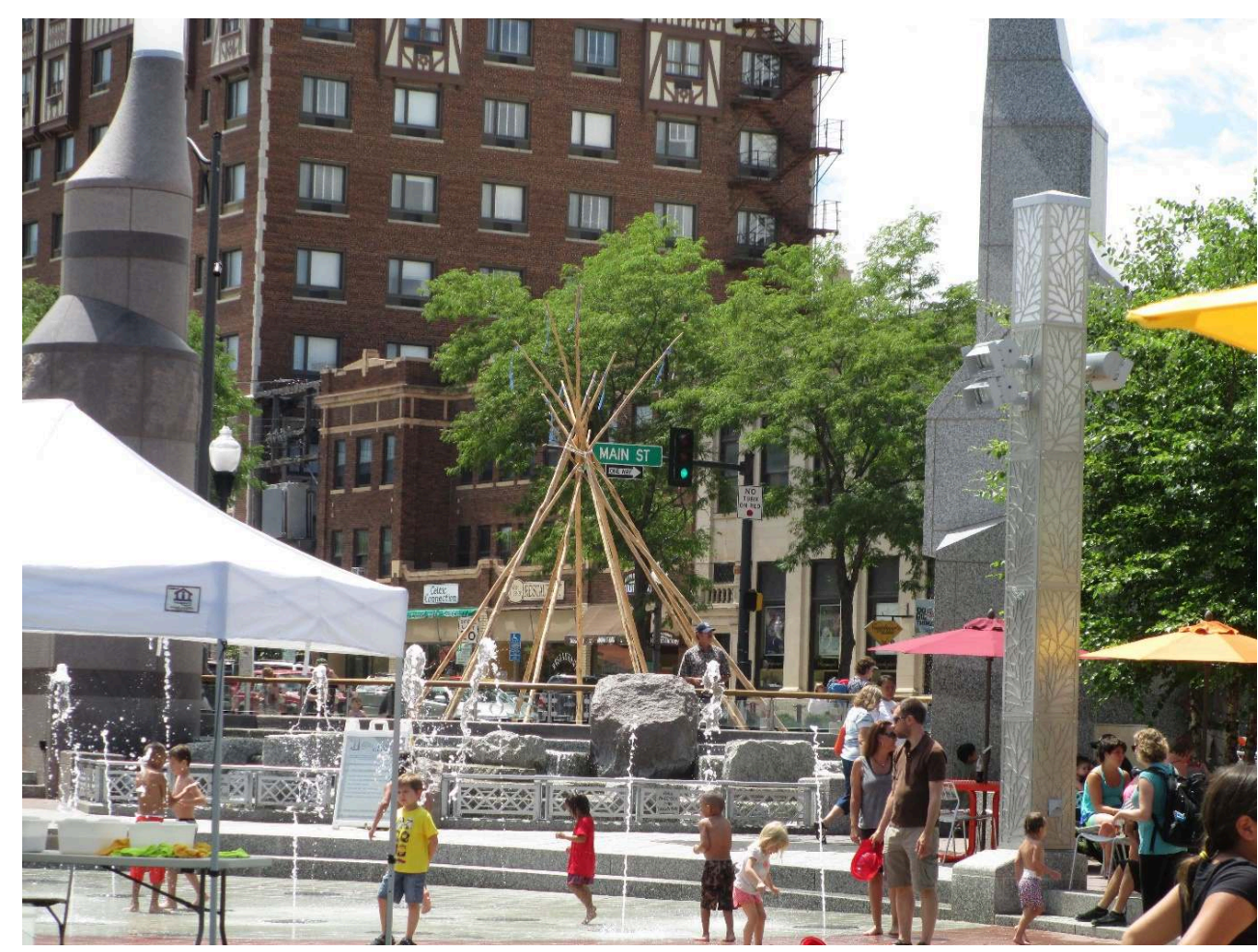

Native POP, 18 juillet 2015

Source : Sandrine Baudry et Céline Planchou

Comme nous l'avons vu, inclure des éléments, même réifiés, transformés, marchandisés, de la culture lakota dans la stratégie touristique de la ville n'est pas nouveau. Mais aujourd'hui les Autochtones sont davantage acteurs de l'incarnation de leur propre culture dans le centre-ville où leur présence a constamment été niée, ce qui permet incontestablement une re-visibilisation bien moins stéréotypée que celle construite auparavant. Ce festival occasionne de nombreuses rencontres et discussions entre Amérindiens et non-Amérindiens (visiteurs et résidents) qui donnent à voir et à penser une réalité autochtone locale plus moderne et plus complexe. Il n'est pas certain cependant que ces évolutions suffisent à transformer durablement des relations historiquement marquées par la violence et des logiques urbaines de marginalisation.

\section{Une visibilité contrôlée}

21 Les diverses formes d'expression de la culture lakota ancrent sans nul doute la réalité autochtone contemporaine dans l'espace urbain. Pour Suzanne Kite, artiste visuelle et compositrice lakota, l'artiste détient un rôle privilégié dans la remise en cause de l'entreprise d'effacement et de négation de la présence amérindienne car il lui revient en premier lieu d'inventer et «d'imaginer des futurs autochtones» (Kite S, 2019: 28). 
Art Alley et Native POP sont des cadres spatio-temporels privilégiés pour l'expression de cet art autochtone fondamentalement politique. Ils permettent aux visiteurs de se confronter à ces imaginaires autochtones. Ils sont également l'occasion, pour certains artistes, de dénoncer publiquement la situation des Amérindiens dans la ville et, plus largement, aux États-Unis. C'est par exemple ce que fait le musicien hip-hop lakota Frank Waln lorsque, entre deux chansons, il s'adresse au public en critiquant un système qu'il qualifie de raciste et en invoquant les droits territoriaux des Lakotas sur les Paha Sapa ${ }^{12}$. Que ces revendications puissent être exprimées en plein cœur d'une border town et entendues, au-delà des spectateurs venus assister au concert (et majoritairement autochtones), par des visiteurs, résidents et touristes qui se promènent dans le nouveau centre-ville, est remarquable

\section{Une expression politique à maîtriser}

Toutefois, force est de constater que cette expression explicitement politique demeure largement limitée et maîtrisée. En d'autres termes, l'Indien artiste peut temporairement devenir un Indien politique et la remise en cause explicite de l'ordre établi est tolérée tant qu'elle reste dans un cadre autorisé et policé. En dehors de ces cadres, les artistes autochtones doivent se faire politiquement discrets puisque le discours politique semble bien toujours pensé comme une transgression et comme nécessairement hostile. Nous citerons l'exemple d'une scène de juillet 2015, lors d'une marche organisée par des parents lakotas en soutien aux « Lakota 57 », des enfants de la réserve voisine de Pine Ridge qui avaient subi des insultes à caractère raciste alors qu'ils assistaient, avec leur classe, à un match de basket-ball à Rapid City (Jesse W., 2016). Cette marche reliait Rapid City High School à la mairie, traversant ainsi le centre-ville (figure 1). Alors que les participants dépassaient Main Street Square, un homme a crié "rentrez chez vous", exprimant ainsi ce sentiment toujours prégnant selon lequel les Amérindiens appartiennent aux réserves et doivent faire profil bas lorsqu'ils sont en ville.

Parce que l'expression politique des Amérindiens de Rapid City est limitée à des lieux et des événements précis, il n'est pas certain que les revendications exprimées dans ces nouveaux forums soient réellement entendues par la population et les institutions locales. Le fait que cette expression soit très maîtrisée peut par ailleurs entraîner une neutralisation du discours qui permettrait au visiteur de ne pas voir, de faire comme si cette réalité n'existait pas (Mercier, 2001). Ces espace-temps joueraient alors le rôle, comme cela peut être le cas pour certaines pratiques festives comme le carnaval, d'un "régulateur social» proposant un "exutoire ludique aux tensions existantes" (Dubois, 1979).

\section{Stigmatisation et criminalisation de la mendicité}

Les mesures visant à limiter la mendicité dans le centre-ville participent également à perpétuer, voire à renforcer, les processus d'exclusion des corps autochtones jugés menaçants et indésirables. Les Amérindiens constituent plus de trois quarts des sansabris à Rapid City (Estes N., $2016: 26$ ) et certains, parmi les plus vulnérables, continuent de vivre dans le centre-ville, où la population est d'ailleurs proportionnellement plus pauvre que dans le reste de la ville (City of RC, 2016 : Appendix D10). Ils demeurent aux marges, entre les berges de Mni Luzahan et différents centres d'hébergement situés de 
l'autre côté de la voie ferrée. Leurs trajets quotidiens entre ces deux pôles viennent d'ailleurs contrecarrer les logiques d'attraction des touristes et investisseurs puisque, pour se rendre dans les centres d'hébergement, ils croisent nécessairement les populations que l'on souhaite désormais retenir. Dans un espace qui se veut «sûr et propre » (City of RC, 2016: 39), la présence visible des sans-abris qui «traînent » au coin des rues et "perturbent» la tranquillité des visiteurs est de plus en plus stigmatisée. Depuis quelques années, des donation stations ont été mises en place à plusieurs carrefours. Ces nouveaux objets du paysage urbain, financés et gérés par Destination Rapid City, incitent les visiteurs à ne pas donner leur argent aux sans-abris mais à y déposer des dons qui seront par la suite redistribués aux centres d'hébergement, cherchant ainsi à faire disparaitre la mendicité de l'espace « public ».

La gestion municipale de la mendicité s'est dans le même temps durcie. En 2019, une ordonnance interdisant la "mendicité agressive» dans le centre-ville a ainsi été adoptée (Zionts A., 2020). Les débats qui ont entouré l'adoption de cette ordonnance ont vu s'opposer ceux qui mettent en avant une pratique qui «effraye» et qui décourage la présence des riverains et des visiteurs à ceux qui dénoncent une mesure stigmatisante qui joue sur les ressorts du stéréotype de l'Indien ivre ${ }^{13}$ (Kent J., 2019). Pour Jim Kent, chroniqueur au Lakota Times, la population locale associe immédiatement la pauvreté et la mendicité aux Amérindiens, et cette mendicité est supposée a priori agressive (ibid). Le langage de la loi viendrait valider une distorsion de la réalité, renforçant ainsi un stéréotype préexistant et criminalisant davantage une population déjà marginalisée.

\section{Une culture non marchandisée difficilement acceptée}

Des initiatives autochtones voient tout de même le jour dans le nouveau centre-ville. Cependant, même lorsque ces initiatives reposent sur l'art ou la culture, elles sont matière à polémique si elles ne servent pas l'intérêt touristique et économique. En 2012, l'essayiste lakota Elizabeth Cook-Lynn décide de lancer un projet afin de rendre hommage à différentes personnalités autochtones (Valandra E., 2017). Le First Nations Sculpture Garden, qui repose sur l'installation de quatre bustes en bronze aux quatre coins d'une promenade en forme de medecine wheel, semble s'inscrire dans la lignée des efforts de redynamisation du centre-ville, mais les discussions autour de son emplacement révèlent cependant différentes logiques. Cook-Lynn a orienté son choix vers Halley Park, un espace enclavé entre deux grandes artères et légèrement en dehors du centre-ville (figure 1). Pour les différents acteurs de la redynamisation urbaine, cet emplacement est peu pertinent car il est trop excentré et ne permet pas d'attirer des visiteurs. Pour Cook-Lynn, il ne s'agit pas de faire venir des touristes mais d'ancrer les Amérindiens dans l'histoire de la ville. Halley Park est en cela hautement symbolique car il est tout près de Mni Luzahan, cœur historique de la présence lakota (Cook-Lynn E., 2012). D'autre part, il s'étend sur une parcelle qui, comme d'autres à travers la ville (autour de Sioux San par exemple), a toujours eu un statut particulier. Ce sont des terres qui, au moment de la création de Rapid City, sont restées sous la juridiction de l'État fédéral afin que ce dernier s'acquitte de ses responsabilités fiduciaires (trust responsibilities) à l'égard des Amérindiens de la ville; responsabilités qui découlent de la signature de traités entre les États-Unis et les nations autochtones de la région ${ }^{14}$. Si des transferts successifs ont progressivement effacé cette histoire, niant dans le même temps la question des responsabilités fédérales fiduciaires, 
l'ouverture de ce parc à cet endroit précis fait resurgir une organisation spatiale qui précède l'existence même de Rapid City. Il ne s'agit donc pas ici de servir l'intérêt touristique et économique, mais d'incarner une réappropriation symbolique du territoire et de rappeler que la ville fut créée sur des terres alors "réservées » aux Amérindiens. Les débats autour du projet, ainsi que les exemples cités plus haut, montrent ainsi que la mise en avant de la culture lakota au sein d'un centre-ville redynamisé ne permet pas une réelle acceptation de la présence autochtone dans l'espace urbain.

\section{Remarques conclusives}

L'étude de cas menée à Rapid City nous permet de proposer des pistes pour comprendre pourquoi les projets urbains centrés autour de la culture ne permettent pas réellement de lutter contre les inégalités sociales et spatiales dont souffrent les Amérindiens dans les border towns. Deux aspects saillants du projet de redynamisation du centre de Rapid City expliquent le décalage entre la revisibilisation de leur culture à des fins touristiques et leur réelle intégration dans la ville : la place persistante des investisseurs privés dans la fabrique de la ville et la définition de la culture comme un phénomène apolitique.

La prépondérance des intérêts privés n'est ni nouvelle, ni remarquable dans cet espace géographique. En effet, la ville de Rapid City a été créée par des entrepreneurs qui ont su tirer profit des retombées économiques de la ruée vers l'or dans Paha Sapa à la fin des années 1870. D'autre part, la méfiance vis-à-vis des pouvoirs publics et la mise en avant de l'entreprenariat privé comme moteur de progrès, pensé avant tout comme progrès économique, sont caractéristiques du mythe fondateur des États-Unis et $a$ fortiori de celui de la conquête de l'Ouest. Ces mythes perdurent aujourd'hui encore dans ces États très largement républicains. C'est d'ailleurs la municipalité elle-même qui a souhaité déléguer la gestion et le financement du centre-ville aux commerçants et entrepreneurs. Cette démarche est indéniablement efficace en termes d'aménagement et d'entretien de l'espace "public » : en effet la fréquentation, notamment piétonne, a augmenté, et les touristes passent plus de temps sur place. Tout ceci entraîne une hausse de la consommation, qui à son tour permet de pérenniser et élargir les investissements et la revitalisation. Le système fonctionne donc dans sa perspective économique, mais nous avons vu que cela ne se traduit que de manière superficielle en termes de progrès social durable, et très peu en termes d'aménagement du reste de la ville. On peut ainsi se demander si de réelles transformations urbaines sociales sont possibles tant que les pouvoirs publics ne s'emparent pas de la question. L'intervention des pouvoirs publics est d'autant plus importante en raison des responsabilités fiduciaires à l'égard des Amérindiens de la ville mentionnées plus haut. Quel échelon de gouvernement s'acquitte de ces responsabilités en ville? Qu'est-il advenu par exemple de ces responsabilités avant tout fédérales, puisque contractées suite à la signature de traités, lorsque l'État fédéral lui-même a transféré la gestion de parcelles ou vendu ces parcelles à la ville? Les Lakotas interpellent de plus en plus les institutions municipales et fédérales lorsqu'ils revendiquent, comme Elizabeth Cook-Lynn par exemple, leur géographie historique ${ }^{15}$. Ils font ainsi ressortir le paradoxe d'un droit à la ville limité pour des résidents dont les droits au territoire sont antérieurs et plus légitimes que ceux d'une border town, définie entre autres par sa genèse illégale. 
Or, la définition de la culture lakota présentée dans le cadre des projets de développement économique joue essentiellement sur la fascination exercée par l'Ouest mythifié et ses habitants réifiés. La culture pensée dans cette perspective encourt le risque de devenir désincarnée, ahistorique et apolitique. Les rapports de domination propres à l'entreprise coloniale autour de la définition de l'autre et de sa culture, et la manière dont ils réifient les corps dominés et les pratiques, croyances, discours et objets qui y sont attachés, ont été largement étudiés (Said, E. 1978 ; Berkhofer R., 1978 ; Boetch G., N. Bancel et P. Blanchard, 2019). Zoey Todd (2019) a également dénoncé la violence exercée par des "alliés " non amérindiens lorsqu'ils récupèrent dans leur propre art des éléments culturels et historiques autochtones. C'est ce processus de désincarnation qui permet jusqu'à ce jour de justifier la marchandisation de l'Indien en niant son humanité. C'est en cela que Native POP, en dépit de son volet commercial (dont en l'occurrence les artistes bénéficient directement), est une expérience d'autant plus frappante dans l'espace public, puisqu'elle ancre la production artistique et les pratiques culturelles dans une réalité contemporaine incarnée et politique. Bien que cette expérience soit circonscrite dans le temps et l'espace, et vendue comme un événement parmi d'autres de la vie culturelle du centre-ville, la présence même des artistes permet d'engager des conversations qui, le plus souvent, poussent leur interlocuteur à reconsidérer son imaginaire territorial en concevant Rapid City non plus comme une porte ouverte vers l'Ouest, mais comme un point au cœur du territoire lakota.

Quant aux initiatives publiques, qui visent cette fois non pas à attirer les touristes mais à apaiser les tensions au sein de la population locale, la définition de la culture qu'elles mettent en avant met l'accent sur le dialogue interculturel. Citons par exemple le recrutement de conseillers culturels lakotas dans la police municipale ou les institutions artistiques. Ces recrutements révèlent que la ville voit dans la méconnaissance culturelle la principale cause du problème social, ce qui tend à masquer les logiques systémiques d'exclusion. Nous pouvons nous demander si cette dissociation entre culture et politique ne cherche pas à nier le pouvoir intrinsèquement politique de toute expression culturelle, surtout lorsqu'elle s'incarne en-dehors du musée. Par exemple, un bâton de guerre traditionnel exposé dans un musée ne suscite $a$ priori pas les mêmes émotions que lorsqu'il est arboré en tête de la marche en soutien aux « Lakota 57 », aux côtés du drapeau de AIM. On voit ainsi que parce que la culture vécue perdure, déborde, s'échappe, elle est perçue comme hostile dans ces border towns car elle «représente un rappel cauchemardesque de la précarité coloniale, la preuve vivante d'une revendication territoriale contradictoire et antérieure » (Estes N., 2016: 24). Afin de sortir de cet antagonisme, il faudrait d'abord reconnaître que «l'espace urbain et les réserves n'ont jamais existé de manière isolée » (Dorries et al., 2019:3). Ce repositionnement impliquerait nécessairement une remise en cause du récit historique dominant qui justifie, jusqu'à aujourd'hui, l'invisibilisation et la marginalisation des Lakotas. Cela permettrait à la ville de tenir réellement compte du fait autochtone dans ses politiques publiques et de prendre en considération les spécificités culturelles et territoriales des résidents lakotas. Seul ce recentrage permettrait de transformer les logiques coloniales d'effacement toujours à l'œuvre dans les efforts récents de redynamisation économique du centre-ville. 


\section{BIBLIOGRAPHIE}

Sources primaires

Annual Report of Commissioner of Indian Affairs, 1898

City of Rapid City, Downtown Area Master Plan, 2016,

https://www.rcgov.org/index.php?option=com_docman\&view=download\&alias=14921-rc-

master-plan-final-9-16\&category_slug=community-planning-division\&Itemid=149, consulté le 16 mars 2021.

City Plan: Rapid City, South Dakota, 1949.

Cook-Lynn, Elizabeth, First Nations Sculpture Walk/Garden Project, Response to Parks and Recreation, 2012.

Entretiens menés entre 2015 et 2017 avec des représentants d'institutions, d'associations et des habitants de Rapid City.

Main Street Square, «A Vibrant Gathering Space that Celebrates the Diversity of Our Community », https://mainstreetsquare.org/, consulté le 22 août 2020.

Rapid City Chamber of Commerce, Rapid City Gateway to the Black Hills of South Dakota, 1932.

Rapid City Summer Nights, « Summer Nights », https://www.rapidcitysummernights.com/, consulté le 24 août 2020.

US Commission on Civil Rights, Discrimination Against Native Americans in Border Towns, 2011.

Valandra, Edward C., « Why a First Nations Sculpture Garden ?», Community for the Advancement of Native Studies, 16 novembre 2017, https://www.academia.edu/35274763/ Why_A_First_Nations_Sculpture_Garden

Articles de presse

Daly, Dan, « Downtown Signs Would Highlight Local History », Rapid City Journal, 20 Février 1996, n.p.

Janson, Donald, « Indians Housed in Dakota Slum », New York Times, 16 juin 1962.

Kent, Jim, « "Aggressive" Panhandling Reality Check-Rapid City vs NYC », 2 mai 2019, consulté le 20 août 2020, n.p. https://www.lakotatimes.com/articles/aggressive-panhandling-reality-checkrapid-city-vs-nyc/

Kentfield, Calvin, « The only thing to do is wipe 'em all out », The New York Times, 15 avril 1973.

KOTATV, « More downtown utility boxes to be wrapped in a work of art », 8 juin 2017, https:// www.kotatv.com/content/news/Downtown-Rapid-City-to-look-more-colorful-427106173.html, consulté le 20 août 2020.

KOTATV, «Questions Raised About Indian Boarding School Land in Rapid City », May 082018 , https://www.kotatv.com/content/news/Questions-raised-about-Indian-Boarding-School-landin-Rapid-City-482138731.html, consulté le 9 octobre 2019.

Lawrence, Tom, « Tourism expert urges Rapid City to "bring downtown to life" », Black Hills Pioneer, 10 janvier 2008. 
Will, Jesse, « A Native American Basketball Tournament Bounces Back », The New Yorker, 31 janvier 2016, https://www.newyorker.com/sports/sporting-scene/a-native-american-basketballtournament-bounces-back, consulté le 16 mars 2021.

Zionts, Arielle, « Rapid City Approves New Panhandling Ordinance », Rapid City Journal, 20 février 2019, https://www.inforum.com/news/government-and-politics/973965-Rapid-City-approvesnew-panhandling-ordinance, consulté le 19 août 2020.

Sources secondaires

Andersen, Chris, « Urban Landscapes of North America » in Robert Warrior (dir.), The World of Indigenous North America, New York and London, Routledge, 2015, p. 149-172.

Anttiroiko, Ari-Veikko, « City Branding as a Response to Global Intercity Competition: Global Intercity Competition ", Growth and Change, vol. 46, n 2, juin 2015, p. 233-52. https://doi.org/ 10.1111/grow.12085, consulté le 20 août 2020.

Barta Julin, Suzanne, « Building a Vacation Land: Tourism Development in the Black Hills during the Great Depression », South Dakota History, vol.35, n 4, hiver 2005, p. 291-334.

Barnd, Natchee Blu, Native Space: Geographic Strategies to Unsettle Settler Colonialism, Corvallis, Oregon State University Press, 2017.

Berkhofer, Robert, The White Man's Indian, Images of the American Indian from Columbus to the Present, New York, Vintage Books, 1979.

Byrd, Jodi, The Transit of Empire: Indigenous Critiques of Colonialism, Minneapolis, University of Minnesota Press, 2011.

Boetsch, G., N. Bancel et P. Blanchard, Sexualités, identités et corps colonisés, $\mathrm{XV}^{e}-\mathrm{XXI} I^{e}$ siècles, Paris, CNRS Editions, 2019.

Dinardi, Cecilia, « Cities for Sale: Contesting City Branding and Cultural Policies in Buenos Aires », Urban Studies, vol. 54, n 1, janvier 2017, p. 85-101. https://doi.org/10.1177/0042098015604079, consulté le 16 mars 2021.

Dorries, Heather, Henry Robert, Hugill David, McCreary, Tyler \& Julie Tomiak, Settler City Limits: Indigenous Resurgence and Colonial Violence in the Urban Prairie West, East Lansing : Michigan State University Press, 2019.

Dubois, Jean, « Carnaval : fête, révolte, spectacle - Pour une histoire », Études françaises, vol. 15, avril 1979, p. 15-34. https://www.erudit.org/en/journals/etudfr/1979-v15-n1-2etudfr1689/036678ar.pdf, consulté le 16 mars 2021.

Estes, Nick, « Off-the Reservation Lakota Life and Death in Rapid City, South Dakota », The Funambulist, $\mathrm{n}^{\circ}$ 5, mai-juin 2016, p. 22-27.

Estes, Nick, « Anti-Indian Common Sense: Border Town Violence and Resistance in Mni Luzahan », in Heather Dorries et al. (dir.), op.cit., p. 44-69.

Hall, Philip, To Have this Land: The Nature of Indian/White Relations, South Dakota, 1888-1891, Vermillon, University of South Dakota Press, 1991.

Kite, Suzanne, « Dreaming a Sovereign Indigenous Future », The Funambulist, $n^{\circ} 24$, juillet-août 2019, p.28-33.

Mainet, Hélène, «Qu'est-ce qu'une petite ville ? Réflexions à partir d'études de cas. (What is a small-sized city? Reflections from case studies) », Bulletin de l'Association de Géographes Français, vol. 85, n 1, 2008, p. 13-22. https://doi.org/10.3406/bagf.2008.2593, consulté le 16 mars 2021. 
Mercier, Arnaud, « Pouvoirs de la dérision, dérision des pouvoirs », Hermès, La Revue, n² 29, 2001, p. 9-18. http://documents.irevues.inist.fr/handle/2042/14482

Ooi, Can-Seng, « The Global Art City » in John Hannigan et Greg Richards (dir.), The Sage Handbookof New Urban Studies, Los Angeles, Sage, 2017, p. 201-216.

Polèse, Mario, « Why (Some) Downtowns Are Back », City Journal, hiver 2014, https://www.cityjournal.org/html/why-some-downtowns-are-back-13622.html, consulté le 16 mars 2021.

Porter, Libby, et Oren Yiftachel. « Urbanizing Settler-Colonial Studies: Introduction to the Special Issue ", Settler Colonial Studies 9, n² 2, 3 avril 2019, p. 177-86, https://doi.org/10.1080/2201473X. 2017.1409394, consulté le 16 mars 2021.

Sager, Tore, « Neo-Liberal Urban Planning Policies: A Literature Survey 1990-2010 », Progress in Planning, novembre 2011, https://doi.org/10.1016/j.progress.2011.09.001, consulté le 24 août 2020.

Said, Edward, Orientalism, New York, Pantheon Books, 1978.

Tallent, Annie D., The Black Hills: Or, The Last Hunting Ground of the Dakotahs, Nixon-Jones printing Company, 1899.

Todd, Zoey, « Decolonizing Prairie Public Art: The Further Adventures of the Ness Namew », in Heather Dorries et al., op.cit., p. 290-309.

Waldner, Lisa K., et Betty A. Dobratz. « Graffiti as a Form of Contentious Political Participation », Sociology Compass, vol. 7, n 5, mai 2013, p.377-89. https://doi.org/10.1111/soc4.12036, consulté le 16 mars 2021.

Weaver, Hilary N. « Urban and Indigenous: The Challenges of being a Native American in the City ». Journal of Community Practice, vol. 20, n 4, octobre 2012, p. 470-88. https://doi.org/ 10.1080/10705422.2012.732001, consulté le 16 mars 2021.

Wilkins, David E., et K. Tsianina Lomawaima, Uneven Ground: American Sovereignty and Federal Law, Norman, University of Oklahoma Press, 2001.

Wolfe, Patrick. « Settler Colonialism and the Elimination of the Native », Journal of Genocide Research, vol. 8, $\mathrm{n}^{\circ}$ 4, 2006, p.387-409.

\section{NOTES}

1. Dans cet article, nous utiliserons le mot "Indien », avec une majuscule et au singulier, pour nous référer à l'Indien désincarné, réifié et mythifié et aux clichés qui y sont associés. Nous préférerons les expressions "amérindien" ou "autochtone ", ou les dénominations tribales, lorsque nous parlons des personnes.

2. Entretien personnel avec une ancienne élue du conseil municipal, 17 juillet 2017.

3. À l'origine, la ville voulait devenir le «Denver des Plaines ", à savoir une plaque tournante économique (City Planning, 1949).

4. Par exemple, la décoration du mobilier urbain avec des œuvres originales d'artistes locaux (KotaTV, 2017)

5. Symbole fondamental dans les cultures des Plaines, représentant le rapport au monde (quatre directions, valeurs fondamentales, éléments naturels, etc.).

6. Entretien avec l'artiste, 29 juillet 2016.

7. Description donnée par le Black Hills Knowledge Network: https:// www.blackhillsknowledgenetwork.org/issue-hub/art-alley.html 
8. Entretien avec Dan Sentfner, 29 juillet 2016.

9. Les Lakotas ne sont qu'un groupe parmi d'autres d'Amérindiens des Plaines, partageant tous un certain nombre de pratiques culturelles.

10. Entretien avec Peter Strong, co-fondateur de la galerie/studios Racing Magpie, 9 juillet 2016.

11. Indian Arts and Crafts Act, 1935.

12. Observation de terrain lors de l'édition de Native POP de juillet 2015.

13. Concernant l'impact du stéréotype de l'Indien ivre sur la criminalisation des corps autochtones, voir A. Randall et B. Randall, "the Criminal Justice and the American Indian ", Indian Historian, vol. 2, n², 1978, p.42-48 ; Joshua Freistadt, « Nu Dumping : Indigenousness and the Racialized Police Transport of the Urban Indian ", in Evelyn J. Peters et Julia Christensen, eds, Indigenous Homelessness : Perspectives from Canada, Australia and New Zealand, Winnipeg, University of Manitoba Press, 2016, version iPad de Kindle, 1655-2162.

14. Sur la question de la responsabilité fédérale fiduciaire voir notamment le chapitre intitulé "With the Greatest Respect and Fidelity ": The Trust Doctrine dans l'ouvrage de David Wilkins et K. Tsianina Lomawaima, Uneven Ground: American Indian Sovereignty and Federal Law, Norman: University of Oklahoma Press, 2001, 64-97.

15. Voir également le projet lancé par the Mniluzahan Okolakiciyapi Ambassadors (MOA) sur l'histoire des terres sur lesquelles s'étendait le pensionnat indien de Rapid City (https:// www.moarapidcity.org/an-inconvenient-truth).

\section{RÉSUMÉS}

Rapid City, dans le Dakota du Sud aux États-Unis, est ce que les chercheurs appellent une border town, ville proche de réserves amérindiennes, caractérisées aujourd'hui encore par la peur et la violence coloniale. Les efforts fournis récemment par des entreprises privées pour générer du développement économique par le tourisme ont mis en avant les cultures autochtones locales, notamment dans l'espace public du centre-ville. Cependant, la visibilité amérindienne plus banale ou politisée, non marchandisable reste ignorée, voire stigmatisée, dans les discours et les pratiques, posant la question d'une possible normalisation de la présence des corps autochtones dans la ville. L'article se termine par une discussion des questions soulevées par l'intégration du fait autochtone dans les politiques de redynamisation urbaine de villes frontières comme Rapid City.

Rapid City, SD, is what researchers call a border town, established close to Native American reservations and still characterized by fear and colonial violence. Recent efforts made by business owners to foster economic development through tourism have led to highlighting local Native cultures, especially in downtown public spaces. Yet, more mundane or politicized - non commodifiable - forms of indigenous visibility remain either ignored or largely stigmatized in discourse and in practice. This raises the issue of a possible normalization of the presence of indigenous bodies in the city. The article ends with a discussion on the relationship between public and private involvement in the making of the city, as well as the relationship between culture and politics, based on a broader reflection about the potential rehabilitation of Native Americans as legitimate inhabitants of a territory they were historically erased from, and fullfledged actors of urban life. 
Rapid City, en Dakota del Sur, es lo que los investigadores llaman una ciudad fronteriza (border town), situada cerca de reservas indígenas y se caracteriza aún por el miedo y la violencia colonial. Los recientes esfuerzos de empresas privadas para generar un desarrollo económico mediante el turismo han puesto en primer plano las culturas indígenas locales, en particular en el espacio público del centro de la ciudad. Sin embargo, su visibilidad más banal o politizada, no mercantilizable, sigue siendo ignorada, incluso estigmatizada, en el discurso y las prácticas, lo que plantea la cuestión de una posible normalización de la presencia de los cuerpos indígenas en la ciudad. El artículo termina con un debate sobre la relación entre lo público y lo privado en la construcción de la ciudad, y la cuestión del vínculo entre la cultura y la política, a través del prisma de una reflexión sobre la posible rehabilitación de los indígenas como ocupantes legítimos de un territorio del que han sido históricamente borrados y actores de pleno derecho de la vida urbana.

\section{INDEX}

Mots-clés : Développement économique urbain, tourisme, amérindiens, discrimination, border town

Palabras claves : Desarrollo económico urbano, turismo, pueblos indígenas, discriminación, ciudad fronteriza

Keywords : Urban economic development, tourism, Native Americans, discrimination, border town

\section{AUTEURS}

\section{SANDRINE BAUDRY}

Sandrine Baudry est Maîtresse de Conférence en civilisation des États-Unis à l'Université de Strasbourg et membre de SEARCH (Savoirs dans l'Espace Anglophone : Représentations, Culture, Histoire). Ses recherches portent sur l'espace public urbain et les dynamiques de privatisation et de domination. Elle a notamment dirigé, avec Aneta Dybska, "Spatial Justice and the Right to the City: Conflicts around Access to Public Urban Space”, European Journal of American Studies, 2015. sbbaudry@unistra.fr

\section{CÉLINE PLANCHOU}

Céline Planchou est Maîtresse de Conférence en civilisation des États-Unis à l'Université Sorbonne Paris Nord (Paris 13 Villetaneuse) et membre du laboratoire Pléiade. Elle s'intéresse aux tenants de la spécificité autochtone aux Etats-Unis et travaille sur les relations entre l'Etat federal, les nations amérindiennes et les Etats membres. Elle a notamment dirigé, avec Marine Le Puloch, "Les nations de l'intérieur-The Nations Within", Revue Française d'Etudes Américaines, 2015. celine.planchou@univ-paris13.fr 